\title{
Normatização de Técnicas e Equipamentos para Realização de Exames em Ergometria e Ergoespirometria
}

\author{
Coordenador \\ Jorge Ilha Guimarães \\ Editores \\ Ricardo Stein \\ Fábio Vilas-Boas \\ Participantes \\ Flávio Galvão \\ Antônio Cláudio Lucas da Nóbrega \\ Renata Rodrigues Teixeira de Castro \\ Artur Haddad Herdy \\ William Azem Chalella \\ Claudio Gil Soares de Araújo \\ Fábio Sândoli de Brito
}

\section{Preâmbulo}

Após meses de contatos via internet, horas de busca por informações referentes ao tópico que nos coube e muito aprendizado, o grupo elaborador da presente normatização, em nome da Sociedade Brasileira de Cardiologia, tem a satisfação de disponibilizar aos cardiologistas brasileiros um documento sui generis.

Muito embora não tenhamos a pretensão de ser dogmáticos, esperamos que os colegas utilizem as recomendações contidas no texto, como fonte para uma otimização em sua rotina ergométrica e/ou ergoespirométrica.

\section{Introdução}

O exercício físico faz parte do cotidiano dos seres humanos, desde os primórdios da sua existência. A aplicação do esforço físico, como método diagnóstico, data do início do século passado e, apesar do desenvolvimento de novas técnicas diagnósticas, ainda ocupa espaço destacado na medicina moderna.

O emprego de técnicas que envolve o exercício com o objetivo de investigar a presença de sinais e sintomas de doenças ou avaliar o resultado de intervenções terapêuticas constitui, o que se chamaria, teste de exercício clínico. No Brasil, após quase 50 anos de uso deste teste propedêutico, consagrou-se o jargão “teste ergométrico". Embora não seja esta a nomenclatura mais adequada, a tradição impõe a manutenção do termo em epígrafe, utilizado neste documento.

O teste ergométrico é um procedimento não invasivo, que pode conferir informações diagnósticas e prognósticas, além de avaliar a capacidade individual para exercícios dinâmicos. Os aparatos disponíveis para a realização de di- ferentes testes, que envolvem o esforço físico, apresentam características distintas, podendo variar de sistemas mais simples a equipamentos com elevado grau de sofisticação tecnológica.

Independentemente do local onde o exame seja realizado, é fundamental que algumas premissas devam ser respeitadas: ambiente adequado, equipamento básico, pessoal treinado e preparo e orientação do paciente, de acordo com o objetivo do exame. É fundamental, ainda, que exista pessoal para atuar em situações de emergência.

O teste ergométrico é um exame extremamente seguro, quando respeitado o julgamento clínico para a sua execução. Do julgamento clínico depende, basicamente, o risco de eventos relacionado a esse exame. Segundo pesquisa realizada no início da década de 80, a taxa de eventos ficaria na ordem de 1 para cada 2500 testes. Entretanto, outros autores classificam o risco como sendo muito menor, ficando na ordem de 0,8:10.000 a 1:10.000 exames. Em população de indivíduos pós - IAM (após 7 dias do evento), a incidência de óbito ficou na taxa de $0,03 \%$ (novo IAM ou ruptura cardíaca). Quando foram relatados os eventos não fatais, a distribuição foi a seguinte (após testes submáximos): PCR ressuscitada ou IAM não fatal $=0,09 \%$; arritmias ventriculares complexas $=1,4 \%$.

Cabe salientar que a taxa de eventos dobrou quando o teste realizado foi limitado por sintomas versus teste submáximo.

Para que esse nível de segurança seja alcançado, os testes deverão ser realizados de acordo com as normas descritas neste documento e discutidas com precisão, conforme as Diretrizes da SBC. Ademais, o exame deverá ser realizado sob a supervisão de médico com as características descritas na tabela 1 .

A ergoespirometria alia, à interpretação clínica e eletrocardiográfica do teste ergométrico convencional, a análise de variáveis ventilatórias, gases expirados e oximetria. Sendo assim, o médico responsável pela realização e interpretação do teste ergoespirométrico deverá apresentar características e conhecimentos mais extensos do que os necessários para a realização do teste ergométrico convencional.

\section{II - Ambiente para a realização do exame - O laboratório}

A sala de exames deverá ser suficientemente ampla para acomodar todo o equipamento necessário à realização dos testes, além de todo o material a ser usado durante eventuais emergências médicas. Não deverá conter mobiliário ou outros objetos desnecessários. A área livre da sala deverá 
A - Características necessárias à realização do exame

Conhecimento das indicações apropriadas do exame.

Conhecimento das contra-indicações, riscos e avaliação do risco do exame em bases individualizadas.

Conhecimento das indicações e contra-indicações de outros testes funcionais e/ou de imagem.

Reconhecimento precoce e tratamento correto das complicações inerentes ao exercício.

Capacidade de realizar todas as manobras básicas e avançadas de reanimação cardiopulmonar e certificação em suporte avançado de vida em cardiologia pela SBC, renovada periodicamente.

Conhecimento dos vários protocolos de testes de exercício e suas indicações.

Conhecimento da fisiologia do exercício e das respostas hemodinâmicas e respiratórias ao exercício físico.

Conhecimento das arritmias cardíacas e habilidade em reconhecer e tratar arritmias graves.

Conhecimento das drogas com ação sobre os sistemas cardiovascular e respiratório e sua influência sobre o exercício físico e sobre as variáveis analisadas durante o exame.

Conhecimento dos princípios e detalhes do exame, inclusive preparo do paciente (limpeza da pele e colocação de eletrodos) e mecanismo de funcionamento do

equipamento utilizado, bem como suas limitações.

Conhecimento dos desfechos a serem atingidos e indicações para interrupção do exame.

B - Características necessárias à interpretação do exame:

Certificado de Habilitação em Ergometria pelo Departamento de Ergometria da Sociedade Brasileira de Cardiologia.

Conhecimento da sensibilidade, especificidade e acurácia diagnóstica do exame em relação às diferentes populações.

Conhecimento de como aplicar o Teorema de Bayes para interpretar os resultados do exame.

Interpretação das alterações eletrocardiográficas relacionadas ao exercício e às diferentes condições patológicas.

Conhecimento de condições que causem falsos-positivos, falsos-negativos e resultados inconclusivos.

Avaliação clínica do paciente durante o exame.

Interpretação das alterações metabólicas relacionadas ao exercício e às diferentes condições patológicas.

Conhecimento do valor prognóstico do exame.

Conhecimento de outros procedimentos diagnósticos e de quando indicá-los.

Conhecimento do equivalente metabólico (MET) e sua relação com intensidade do esforço.

Adaptado por Castro RRT, Nóbrega ACL, Vilas-Boas F e Stein R, de American College of Cardiology/ American Heart Association - Clinical competence statement on stress testing. J Am Coll Cardiol 2000;36:1441-53.

permitir a circulação de, pelo menos, 3 pessoas, caso ocorra necessidade de acesso a situações emergenciais. Uma área reservada para o preparo do paciente também é importante, constando idealmente, com vestiário e banheiro.

O laboratório deverá ser bem iluminado, limpo e com controle da temperatura ambiente (entre 18 e $22^{\circ} \mathrm{C}$ ) e umidade relativa do ar (ente 50 e $70 \%$ ). Esses valores devem ser obtidos através de equipamentos de refrigeração/aquecimento e umidificadores/desumidificadores e aferidos através de higrômetro e termômetro. Quando realizados testes com medidas simultâneas da ventilação pulmonar e de gases expirados (ergoespirométricos), a pressão barométrica também deverá ser registrada.

Durante testes ergoespirométricos é impossível a comunicação verbal do paciente com o examinador, sendo conveniente a utilização de um pôster apresentando a escala de Borg modificada, para a indicação manual da sensação subjetiva de cansaço. Essa peculiaridade da ergoespirometria deverá ser explicada ao paciente antes do início do teste. Mesmo em laboratórios onde se realizam apenas testes ergométricos convencionais, sugerimos que a escala de Borg esteja no campo visual do paciente durante a realização do exame.

\section{Equipamentos para a execução de Testes}

III.1 Teste ergométrico(TE) - Preferencialmente, um computador central deverá controlar o funcionamento do ergômetro (esteira ou cicloergômetro) e demais equipamentos periféricos (oxímetro, monitor de pressão), todos eles interfaceados.
Na atualidade, o TE se rende à importância do computador, mas é necessário e fundamental que todo e qualquer sistema esteja devidamente adequado para a promoção de um exame fidedigno. Para tanto, existem recomendações para a especificação dos equipamentos digitais.

a) Ergômetro -Os ergômetros devem ser, preferencialmente, eletrônicos ou eletromagnéticos e dispor de interface de comunicação com o computador central, através de saída analógica ou digital, para onde deverão ser enviados dados de velocidade, inclinação, ciclos, etc. e recebido os comandos de variação de carga.

Esteira - * Requisitos obrigatórios em uma esteira ergométrica para utilização em teste de esforço: a esteira deverá ser controlada eletronicamente e estar apta para suportar pacientes com diferentes pesos corpóreos (pelo menos até $157,5 \mathrm{~kg}$ ); deve oferecer a possibilidade de regulagem da velocidade, elevação (inclinação) e tempo de exame, observando-se a velocidade mínima de $1,6 \mathrm{~km} / \mathrm{h}$ e máxima de, no mínimo, $12,8 \mathrm{~km} / \mathrm{h}$, além de inclinação variando de zero até, pelo menos, 24\%; a área de trabalho deve permitir tanto a caminhada quanto a corrida (a plataforma da esteira deve ter, no mínimo, $127 \mathrm{~cm}$ de comprimento e 40,64 cm de largura); recomenda-se a presença de apoios laterais e frontal, uma vez que esses dispositivos são importantes na adaptação do paciente à esteira; recomenda-se que o equipamento disponibilize programação automática de velocidade, de inclinação e do tempo de exame, com intervalos de, no mínimo, um minuto entre os estágios do exame; compensação automática de velocidade em função do peso do paciente testado é outro requisito importante. Em outras palavras, o equipamento irá aplicar maior força para compensar a carga 
(peso do paciente), procurando manter sempre a velocidade exata solicitada no protocolo.

Sugerimos que a esteira ergométrica também disponibilize: controle manual ou automático, através de comando próprio ou de interface com um computador (no caso de sistema de ergometria computadorizado); programação através do comando da esteira ou do computador (no caso de sistema de ergometria computadorizado), de protocolos em rampa com indicação da velocidade inicial e final, inclinação inicial e final, tempo de exame, sexo do paciente, coeficiente de aumento de carga e consumo em METs previsto; julgamos ser de extrema importância que as esteiras ergométricas sejam equipadas com chave de desligamento de emergência, devendo a mesma ser de fácil acesso tanto para o médico (operador) quanto para o paciente. * São preferíveis as chaves automáticas conectadas ao paciente por um pequeno cabo, que desliga o sistema caso o mesmo se afaste demasiadamente do braço frontal da esteira, sofra uma queda ou não consiga vencer a velocidade imposta pelo protocolo escolhido, além de ser útil em caso de ocorrer algum mal súbito que determine a imediata parada da esteira.

Cicloergômetro - O cicloergômetro pode ser uma alternativa à esteira quando se realiza exame em paciente com limitações ortopédicas, neurológicas ou vasculares periféricas. Além disto, a qualidade do traçado eletrocardiográfico e a da medida da pressão arterial tendem a ser melhores do que na esteira. Desta forma, alguns serviços podem preferir a utilização do cicloergômetro à esteira. Devemos ressaltar que as respostas fisiológicas ao exercício em cicloergômetro diferem daquelas ao exercício em esteira, o que deverá ser levando em conta na interpretação do exame. Por exemplo, o consumo máximo de oxigênio é cerca de 5 a $20 \%$ mais baixo, e a resposta pressórica por carga de trabalho é proporcionalmente maior do que na esteira.

Dois tipos de cicloergômetros, no tocante ao sistema de determinação da resistência, estão disponíveis no mercado: os com frenagem mecânica e os com frenagem eletromagnética. Os cicloergômetros com frenagem mecânica são mais baratos e leves, entretanto é necessário que o paciente mantenha uma velocidade fixa de pedaladas para manter o trabalho constante. Por outro lado, os cicloergômetros com frenagem eletromagnética são mais caros e menos portáteis, mas dispõem de ajuste interno de resistência, capaz de manter o trabalho de acordo com a velocidade de pedaladas. Independente do tipo de frenagem, o cicloergômetro utilizado deverá apresentar a capacidade de incrementos no trabalho, seja de forma automática ou manual. O cicloergômetro deverá apresentar guidom e selim ajustáveis de acordo com a altura do paciente.

Cicloergômetro de braço - O ergômetro de braço representa uma alternativa para a realização de testes diagnósticos em indivíduos com incapacidade funcional de membros inferiores. Entretanto, sua sensibilidade para o diagnóstico de doença arterial coronariana é menor que a dos testes realizados em esteira. Além disso, a ergometria de braço pode ser utilizada na avaliação ocupacional de indivíduos cujo trabalho exija, basicamente, movimentação dos membros superiores e porção superior do tronco.
O ergômetro de braço pode ser fabricado com esta função específica ou ser adaptado de uma bicicleta ergométrica comum, substituindo-se seus pedais por manoplas. Pode ter frenagem mecânica ou eletromagnética.

b) Monitorização da pressão arterial - $O$ método auscultatório de aferição da pressão arterial é o mais confiável durante o exercício. O manômetro de coluna de mercúrioé o aparelho recomendado, ao invés do aneróide, por ser mais acurado e de mais fácil manutenção. O manômetro deverá ser colocado na altura do coração do paciente.

Monitores não invasivos de pressão podem ser utilizados desde que exista tecnologia validada para sua aplicação durante o exercício.

III.2 Equipamentos para realização da ergoespirometria - No teste de esforço cardiopulmonar, são geradas, além das informações decorrentes de um teste ergométrico, informações relativas à ventilação e às frações expiradas de oxigênio $\left(\mathrm{FEO}_{2}\right)$ e de gás carbônico $\left(\mathrm{FECO}_{2}\right)$. Outras variáveis importantes são derivadas pelo sistema integrado ao computador. São elas:

1) consumo de oxigênio $\left(\mathrm{VO}_{2}\right)$ e produção de gás carbônico $\left(\mathrm{VCO}_{2}\right)$;

2) equivalentes ventilatórios do oxigênio $\left(\mathrm{VE} / \mathrm{VO}_{2}\right) \mathrm{e}$ do gás carbônico ( $\left.\mathrm{VE} / \mathrm{VCO}_{2}\right)$;

3) pulso de oxigênio $\left(\mathrm{VO}_{2} / \mathrm{FC}\right)$;

4) quociente respiratório ( $\mathrm{RQ}$ ou $\left.\mathrm{R}=\mathrm{VCO}_{2} / \mathrm{VO}_{2}\right)$; $\mathrm{Ob}$ servação: Utiliza-se a sigla RQ até que o $1^{\circ}$ limiar ventilatório seja atingido. Após o primeiro limiar ventilatório ser atingido, usa-se a sigla $\mathrm{R}$.

Medida da Ventilação - O aparelho para medida da ventilação deverá ter acurácia suficiente para medidas de diferentes volumes e velocidades de fluxos e baixas resistência e inércia. Além disso, é desejável que o aparelho permita sua conexão ao computador, para maior facilidade da correlação dos dados obtidos.

A medida da ventilação durante o exercício requer que o indivíduo testado tenha suas narinas fechadas por um clipe nasal e que o bocal não permita qualquer escape de ar. O espaço morto do equipamento também é importante $($ máximo $=100 \mathrm{ml})$.

Para realização de medidas precisas, é necessário que seja determinada a umidade relativa do ar, realizando-se os ajustes para temperatura e pressão padronizados (ou seja, STPD).

Atualmente, a análise de gases é realizada "on-line". Vários tipos de fluxômetros podem ser utilizados: transdutores de massa, pneumotacômetros de Fleish, anemômetros, entre outros. Esses sistemas permitem medidas das trocas gasosas a cada ciclo respiratório (respiração por respiração - do inglês "breath by breath"). Com estes sistemas, as respostas do paciente tornam-se disponíveis imediatamente, e, com o sistema acoplado ao computador, as medidas são continuamente disponibilizadas na tela (durante o exame).

Os pneumotacômetros medem as reduções de pressão 
geradas pelo fluxo através de um tubo. A relação entre fluxo e queda da pressão é analisada através da Lei de Bernoulli (o fluxo é proporcional à raiz quadrada da diferença de pressão). Essa lei permite a medida do fluxo com o pneumotacógrafo. Os transdutores de volume à turbina medem o fluxo bidirecional de ar na boca. Anemômetros consistem em um tubo fino com um arame aquecido em seu interior. Conforme o ar flui pelo tubo, ele esfria o arame. O volume de fluxo do ar é proporcional à quantidade de eletricidade necessária para reaquecer o arame.

Análise dos gases - Os dois tipos de analisadores de oxigênio comumente utilizados são: paramagnético e eletroquímico. Na verdade, esses analisadores medem pressões parciais: o gás é expresso como porcentagem através da razão entre a pressão parcial de oxigênio e a pressão barométrica.

Os analisadores eletroquímicos são os mais utilizados nos sistemas automatizados atualmente disponíveis. Geralmente, esses sistemas utilizam uma célula de óxido de zircônio aquecida a temperaturas extremas. Uma corrente será gerada proporcionalmente às diferenças na pressão parcial de oxigênio em qualquer dos lados da membrana semipermeável da célula (isto é, diferença entre o ar da sala e o ar dentro do sensor). Analisadores paramagnéticos medem alterações no campo magnético causadas por mudanças nas concentrações de oxigênio. Esse tipo de sistema é freqüentemente utilizado para medidas em campo (aparelhos portáteis), mas seu tempo de resposta é lento, por isso esse sistema de análise não costuma ser utilizado nos sistemas metabólicos de exercício.

O dióxido de carbono, geralmente, é medido por um analisador infravermelho. Este sistema baseia-se na teoria de que o dióxido de carbono absorve energia de uma porção específica do espectro infravermelho. Assim, a luz infravermelha passará por uma célula contendo determinada quantidade de dióxido de carbono, e o volume de luz transmitido é comparado com um valor constante conhecido. A diferença será proporcional à pressão parcial de dióxido de carbono na amostra analisada. Os sensores infravermelhos para medida do dióxido de carbono são sistemas bem validados e têm tempos de resposta rápidos. Desta forma, esse é o sistema utilizado em praticamente todos os analisadores metabólicos comercialmente disponíveis.
Como os sistemas disponíveis apresentam diferentes especificações para realização da calibração, deve-se sempre seguir o protocolo de calibração indicado no manual do equipamento. Para garantir a exatidão dos valores medidos, o analisador deve prover meios de executar sua calibração tanto por meios automáticos, quanto por meio de misturas de gases para calibração.

Para prevenir a contaminação entre pacientes, as peças que entram em contato com o paciente devem ser descartáveis ou serem adequadamente preparadas, com a utilização de soluções enzimáticas desinfetantes.

\section{Competência clínica na realização de exames}

IV.1. Teste Ergométrico - Para a realização de teste ergométrico, o cardiologista deve buscar possuir as habilidades descritas na tabela 1, parte A. Para interpretar os resultados, é necessário ainda o conhecimento da parte B, da mesma tabela.

IV. 2. Teste ergoespirométrico - Por envolver maior complexidade das variáveis e parâmetros a serem analisados e interpretados, bem como maior sofisticação tecnológica dos equipamentos utilizados, para obter competência clínica para realização de testes ergoespirométricos uma gama extra de habilidades precisa ser desenvolvida. De um modo geral, todas as habilidades necessárias para a realização do teste ergométrico também são necessárias para a realização do teste ergoespirométrico, acrescidas de algumas outras, conforme o descrito na tabela II.

\section{Treinamento mínimo necessário para a realização de exames}

V.1. Teste ergométrico -Diversos médicos adquiremo conhecimento necessário para a realização de testes ergométricos durante treinamento informal, com outros colegas ou em cursos específicos de curta duração. Dessa forma, é fundamental a definição de normas de treinamento mínimo, que sejam seguidas por todos os serviços que se propõem a habilitar o cardiologista nessa área. a) Disponibilizaçãode

Tabela II. Habilidades para a realização competente de teste ergoespirométrico.

A - Características necessárias à realização do exame

Todas as existentes na tabela 1 , item $\mathbf{A}$, acrescidas de:

Conhecimento dos procedimentos de calibração do equipamento e manipulação de gases.

Conhecimento das técnicas de realização de espirometria simples.

Habilidade para reconhecer problemas técnicos na coleta de dados respiratórios (vazamento de gases, entupimento de linhas, monitorização adequada).

B - Características necessárias à interpretação do exame:

Todas as descritas na tabela 1 , item $\mathbf{B}$, acrescidas de:

Conhecimento aprofundado de fisiologia respiratória, cardiovascular e circulatória e da interação entre os três sistemas.

Conhecimento de interpretação de espirometria simples.

Conhecimento do metabolismo de substratos energéticos em diferentes condições (saúde e doença, repouso e exercício)

Conhecimento aprofundado de fisiopatologia da limitação funcional na saúde e na doença, para permitir identificação dos mecanismos limitantes do exercício.

Conhecimento sobre o efeito de intervenções terapêuticas sobre as variáveis analisadas no teste.

Conhecimento da interpretação das variáveis dispostas sob a forma tabular e gráfica, incluindo todas as variáveis e parâmetros obtidos direta e indiretamente. 
laboratório adequado, conforme as normas da SBC para laboratórios de ergometria. b) Profissional orientador com habilitação em Ergometria pelo SBC/DERC.c) Realização de 50 testes ergométricos, sob supervisão, incluindo todas os itens descritos na tabela 1. d) Certificação em suporte avançado de vida em cardiologia (SAVC). e) Emissão de certificado de conclusão de treinamento pelo profissional responsável, acreditado pelo SBC/DERC.

V.2. Teste ergoespirométrico-De forma semelhante ao que acontece com o teste ergométrico, com o agravante de não fazer parte da grande maioria dos programas de residência médica, a competência clínica para realização de testes ergoespirométricos costuma ser alcançada através de estágios em serviços com grande volume.

$\mathrm{O}$ aspecto principal que deve ser atentado por aqueles que buscam treinamento formal nessa área é o perfil da clientela avaliada no serviço onde pretende ser treinado. Existe grande variabilidade nos formatos dos programas de treinamento, que enfatizam aplicações especializadas desse método, dependendo da característica da clientela do serviço onde se insere o programa. Alguns serviços tendem a atender predominantemente atletas, outros cardiopatas, outros indivíduos normais e outros, ainda, pneumopatas. O ideal seria um treinamento em todos as populações ou, predominantemente, na população em que o cardiologista pretende atuar.

Dessa forma, é fundamental a definição de normas de treinamento mínimo, que sejam seguidas por todos os serviços que se propõem a habilitar o cardiologista nessa área do conhecimento. Além das normas descritas para ergometria, é preciso:

1. Disponibilização de laboratório adequado, conforme as normas da SBC para laboratórios de ergometria, enfatizando a necessidade de controle rigoroso da temperatura e umidade da sala.

2. Realização de 50 testes, sob supervisão, incluindo todos os itens descritos nas tabelas $1 \mathrm{e} 2$.

\section{Manutenção da competência}

Para manter sua competência nesta área, recomendamos que o médico realize um mínimo de 100 exames ergométricos convencionais e 50 exames ergoespirométricos por ano. Além disso, também é recomendável a realização de um curso de suporte avançado de vida em cardiologia com atualizações periódicas.

\section{Normatização de equipamentos}

VII.1.Equipamentos para a execução do Teste Ergométrico - Desde 1959, quando, pela primeira vez, um computador foi utilizado para análise eletrocardiográfica, sistemas cada vez mais sofisticados têm surgido no mercado. No que diz respeito à análise do traçado eletrocardiográfico propriamente dito, os dados têm sido obtidos de forma digital.
Isso é especialmente importante em relação às medidas de duração e amplitude dos diversos intervalos, ondas e segmentos. $\mathrm{O}$ uso do computador durante TE constitui ferramenta indispensável, possibilitando o estudo de variáveis de difícil obtenção manual e/ou visual. Os sistemas computadorizados também melhoram significativamente o sinal eletrocardiográfico quanto ao ruído por interferência da rede elétrica, atividade muscular e oscilações da linha de base, uma vez que filtros digitais foram desenvolvidos e utilizados com esse fim.

Na análise automática do eletrocardiograma de repouso, os sistemas existentes são confiáveis, embora sejam passíveis de incorreções, principalmente quando existem alterações da repolarização ventricular, necessitando sempre de reavaliação por cardiologista experiente. No que diz respeito à análise automática realizada durante o TE, tal prática não deve ser desvinculada da avaliação visual do traçado, sendo recomendável que o ergometrista executor procure otimizar sua impressão através da sinergia entre os dois métodos de análise.

Uma das principais indicações do TE relaciona-se ao diagnóstico da doença arterial coronariana (DAC). A análise computadorizada, através da instituição de diversos índices e escores, não se mostrou devidamente eficiente em termos de incremento na sensibilidade e especificidade quando comparada à análise visual. Entretanto, entre os escores computadorizados, aqueles que incluem variáveis clínicas possuem maior poder diagnóstico e prognóstico em portadores de DAC do que os que se baseiam apenas em variáveis eletrocardiográficas.

Para a execução do teste ergométrico convencional ou do teste cardiopulmonar, faz-se necessária a presença de um eletrocardiógrafo. Esse equipamento é classificado junto à Agência Nacional de Vigilância Sanitária (ANVISA) como “equipamento correlato". Sua certificação junto àquele órgão, tanto quanto à qualidade do produto, bem como à conformidade do seu processo de produção, é obrigatória. $\mathrm{O}$ eletrocardiógrafo deve possuir as seguintes características, entre imprescindíveis e desejáveis:

VII.1.1. Quanto às suas características técnicas -a) Quanto às derivações eletrocardiográficas: Para monitorização e registro do ECG durante o teste ergométrico, recomenda-se que, quando o teste for utilizado para fins de diagnóstico ou prognóstico, sejam empregadas, no mínimo, 3 derivações, simultâneas, em tempo real, uma vez que o uso de 1 derivação (CM5 ou CC5) pode ser menos sensível na identificação de distúrbios do ritmo e/ou da condução.

As combinações mais freqüentemente utilizadas são: 3 derivações - normalmente sendo utilizadas CM5, D2M e V2M; 12 derivações - quando são utilizadas as 12 derivações clássicas (DI, DII, DIII, aVR, aVL, aVF, V1 a V6), posicionadas segundo sugerido por Mason-Likar; 13 derivações - quando são utilizadas as 12 derivações clássicas mais a derivação CM5, comum $11^{\circ}$ eletrodo localizado no manúbrio; 16 derivações, em que são utilizadas as 13 derivações anteriores mais 
três precordiais direitas (validade externa ainda depende de estudos mais aprofundados sobre o uso das precordiais direitas em associação às 13 derivações tradicionais).

No aspecto relacionado à taxa de amostragem do sinal, deve-se ter ciência de como esse sinal eletrocardiográfico é armazenado e de quantos bits é composta a unidade de armazenamento. Para que um computador possa analisar e armazenar o sinal eletrocardiográfico, seu nível de voltagem deve ser medido e convertido para o formato digital a determinados intervalos de tempo, e esse valor armazenado adequadamente. Isto define a taxa de amostragem do sinal quantas vezes por segundo o sinal deve ser medido e convertido -, e sua resolução - quantos “bits" são utilizados para armazenar cada medida. A taxa de amostragem necessária para se representar o traçado eletrocardiográfico deve ser de, no mínimo, 300 amostras por segundo, e o armazenamento deve ser realizado com uma resolução de 12 bits. Essa taxa de conversão analógico-digital de, pelo menos, 300 amostras por segundo deve ser a taxa de cada canal.

b) Quanto à filtragem do sinal: O eletrocardiógrafo deve conter filtros para atenuação de interferências da rede elétrica, atenuação de flutuações na linha base do traçado e atenuação de artefatos musculares indesejados. Esses filtros devem possuir características tais que interfiram o mínimo possível com o sinal eletrocardiográfico - tais como resposta plana em fase e "ripple" menor ou igual a $0,5 \mathrm{~dB}$. Esses filtros devem poder ser desligados ou religados a qualquer momento durante a execução do exame.

c) Quanto às características funcionais: O eletrocardiógrafo deve possibilitar o registro do traçado eletrocardiográfico a qualquer momento durante o teste, a critério do médico. Os registros devem poder ser feitos de forma automática, em intervalos de tempo pré-determinados (por exemplo, ao final de cada estágio), e/ou de forma manual, em qualquer momento. Os traçados devem ser impressos em papel com fundo milimetrado, com informações sobre a sensibilidade utilizada para o registro, sendo necessárias sensibilidades de $5 \mathrm{~mm} / \mathrm{mV}, 10 \mathrm{~mm} / \mathrm{mV}$ e $20 \mathrm{~mm} / \mathrm{mV}$. Quantoà velocidade de registro, deve ser possível, pelo menos, as velocidades de $25 \mathrm{~mm} / \mathrm{s}$ ou $50 \mathrm{~mm} / \mathrm{s}$. A presença de um traçado registrado continuamente, para fins de exploração de presença de arritmias não registradas durante o exame é desejável.

VII.1.2. Quanto à sua qualidade - É necessária a existência de um Relatório para Análise da Qualidade e da Certificação do Equipamento (RAQCE) aprovado por órgão competente credenciado pela ANVISA. Esse relatório é a base da certificação junto à ANVISA e atesta os seguintes pontos: a qualidade do produto e a adequação do processo de fabricação ao Manual das Boas Práticas para Fabricação e Equipamentos Eletromédicos, editado pela ANVISA; a sua conformidade quanto às normas de segurança elétrica NBR ISO-IEC601.1 e sua sub parte NBR ISO-IEC601.1-25, que garante a segurança elétrica tanto do paciente quando do operador.

\section{Programas de computador para execu- ção do teste ergométrico}

VIII.1. Teste ergométrico - O teste ergométrico (TE) comumente tem sua execução controlada por um programa de computador. Muitas das funções centrais de um TE dependem totalmente do programa de computador e, portanto, a qualidade final do procedimento é fortemente influenciada pela qualidade do programa de computador utilizado ("software").

Hoje em dia, estão disponíveis no mercado diferentes sistemas para execução do TE, sendo freqüente a combinação do uso de um eletrocardiógrafo digital com um programa de computador. Na escolha de um programa de computador para TE devem ser consideradas as possibilidades técnicas a seguir.

a) Flexibilidade - O programa deve ser flexível, permitindo a configuração de itens do TE, tais como cadastro de novos protocolos, bibliotecas de frases, diferentes sistemas de derivações do ECG tais como 3, 12 ou 13 derivações e utilização opcional de filtros do traçado. Considerando-se as diferenças existentes por parte dos médicos na emissão de laudos, na escolha do número de derivações empregadas, nos protocolos e no uso ou não de filtros, a flexibilidade do programa de computador é de elevada significância.

b) Recursos: O programa de computador deve oferecer minimamente os seguintes recursos: recebimento e processamento do sinal de ECG vindo do eletrocardiógrafo; visualização do ECG durante o TE; cálculo da frequiência cardíaca máxima e submáxima; registro do traçado em memória ou em papel; controle de ergômetros; controle de protocolos do TE; filtragem do sinal eletrocardiográfico para redução de interferências e ruídos; controle das etapas do TE e do tempo de teste; cálculo de médias dos complexos do ECG (opcional); salvamento dos canais de ECG para interpretação posterior (opcional); Medidas do segmento ST durante o TE (opcional); Elaboração dos cálculos das variáveis do TE (opcional); Suporte à emissão de laudo final do TE, sendo que o laudo deve ser dado em português; Armazenamento do exame para posterior recuperação (opcional)

c) Confiabilidade-O programa de computador deve ser confiável e oferecer uma grande estabilidade no uso. Deve existir uma política de atualizações de versões do programa, garantindo a correção de erros bem como a implementação de novos recursos, além de sua atualização com a evolução natural de computadores e sistemas operacionais.

d) Suporte Técnico - O programa de computador deve contarcom uma estrutura de suporte técnico apta a mantê-loem funcionamento de acordo com as especificações de fábrica.

VIII.2. Ergoespirometria-A ergoespirometria exige do programa de computador a união dos resultados de um teste ergométrico convencional com os resultados advindos de um analisador metabólico de gases e de um oxímetro de pulso. No 
que diz respeito aos resultados do TE, as exigências e necessidades do programa de computador são exatamente as mesmas do item anterior. O programa de computador para a ergoespirometria deve ser capaz de ordenar a grande quantidade de informações coletada e mostrar, em tempo real e de forma integrada, todos os dados de maneira a possibilitar a condução e o diagnóstico da ergoespirometria.

a) Recursos - O programa de computador para a ergoespirometria deve possuir, minimamente, os seguintes recursos: a) Todos os recursos do programa de teste ergométrico convencional; b) Capacidade de receber os dados oriundos do analisador de gases e de calcular as variáveis necessárias ao TECP, a saber: Ventilação em BTPS; $\mathrm{VO}_{2} ; \mathrm{o}$ $\mathrm{VCO}_{2}$; Pulso de oxigênio, $\mathrm{VO}_{2} / \mathrm{FC}$; Potência em Watts; Equivalentes respiratórios de $\mathrm{O}_{2}$ e $\mathrm{CO}_{2}$; Quociente respiratório; Frações expiradas de $\mathrm{O}_{2}$ e $\mathrm{CO}_{2}$; Escala de percepção de esforço de Borg; c) Visualização dos dados sob a forma numérica e gráfica; d) Possibilidade de marcação do limiar anaeróbio, do ponto de compensação respiratória e do esforço máximo; e) Capacidade de receber, em tempo real, os dados do oxímetro de pulso e de sua apresentação de forma numérica e forma gráfica; f) Cálculos e apresentação de resultados da ergoespirometria de forma ordenada e clara; g) Relatórios contendo os resultados numéricos e gráficos das variáveis da ergoespirometria; h) Laudo orientado para ergoespirometria, com biblioteca de frases e em português.

O programa de computador para ergoespirometria deve obedecer aos mesmos requisitos de flexibilidade, confiabilidade e suporte técnico exigidos do programa para TE.

\section{Orientações ao cliente}

As seguintes recomendações devem ser obtidas pelo paciente junto ao médico assistente: a) motivo do teste ergométrico; b) decidir sobre a suspensão ou manutenção da medicação vigente. Na primeira condição, designar ao laboratório o tempo necessário para suspensão de medicamentos.

Observação: Considerando-se que o fenômeno de rebote pode ser evidenciado na suspensão abrupta dos betabloqueadores e de alguns agentes anti-hipertensivos, salienta-se a necessidade de retirada gradual dos fármacos antes do exame.

O preparo da pele do paciente, antes da aplicação dos eletrodos é ponto fundamental para garantir a qualidade do exame. Os eletrodos de cloreto de prata-prata ("silver-silver chloride") são recomendados em função de sua capacidade

\begin{tabular}{|lc|}
\hline \multicolumn{2}{|c|}{$\begin{array}{c}\text { Quadro I - Tempo de suspensão de medicamentos para realização do } \\
\text { TE, quando a finalidade é diagnóstica. }\end{array}$} \\
\hline Medicação & Dias de suspensão prévia \\
Amiodarona & 30 \\
Betabloqueadores & De 4 a 8 \\
Bloqueadores dos canais de cálcio & De 1 a 4 \\
Digoxina & De 7 a 10 \\
Nitrato & 1 \\
\hline
\end{tabular}

de minimizar os artefatos gerados pelo exercício. Os cabos do eletrocardiógrafo deverão ser leves e poderão ser fixados junto ao paciente, minimizando os artefatos.

\section{Preparo para as situações de emergência}

Apesar de seguro, o teste ergométrico apresenta riscos potenciais, ainda que raros, conforme já discutido. Todo o laboratório de exercício deverá ter um plano de emergência estabelecido, baseado nos protocolos universalmente aceitos da "American Heart Association" para suporte de vida básico e avançado. Até mesmo a forma como serão removidos pacientes instáveis para um hospital adequado deverá estar prevista nesse plano. Todos os profissionais alocados no laboratório de exercício devem estar adequadamente treinados para situações de emergência.

As tabelas 4 e 5 listam os equipamentos e medicações de emergência indispensáveis em qualquer laboratório de exercício.

\section{Registros eletrocardiográficos}

Os registros devem obedecer a uma seqüência lógica com a obtenção dos seguintes traçados: repouso; durante cada estágio de exercício ou a critério médico; recuperação; na presença de arritmias, documentando e relatando sua provável origem, complexidade, frequiência e momento de aparecimento, assim como quando de distúrbios da condução.

Tabela IV- Equipamento de emergência indispensável no laboratório de exercício

Cardioversor/desfibrilador portátil

Cilindro de oxigênio

Máscara de venturi

Cânula nasal, máscara para macronebulização

Laringoscópio (cabo e pelo menos uma lâmina curva e uma lâmina reta) Mandril

Tubos para intubação orotraqueal de diferentes tamanhos

Ambu

Escalpes, jelcos, siringas e agulhas para administração de medicamentos Esparadrapo

Aspirador (portátil)

Equipamentos de proteção individual (luvas, óculos, etc)

Tabela V- Medicações indispensáveis no laboratório de exercício

Adenosina
Amiodarona
Atropina
Adrenalina
Procainamida
Verapamil
Dopamina
Dobutamina
Lidocaína
Nitroglicerina (sublingual ou spray)
Broncodilatadores
Soro fisiológico a $0,9 \%$
Solução de glicose a $25 \%$ ou $50 \%$




\section{Sinais e sintomas}

Devem ser observados e anotados sinais e sintomas do paciente, tais como palidez, tontura, sudorese, estafa física e dispnéia, relacionando-os à condição hemodinâmica e à resposta eletrocardiográfica frente ao esforço. Há necessi- dade de caracterização pormenorizada do sintoma dor torácica, avaliando seu modo de aparecimento, momento, intensidade, evolução, caráter, fenômenos associados e irradiação. As auscultas cardíaca e pulmonar, além de obrigatórias no exame clínico inicial, devem ser, obrigatoriamente, repetidas no pós-esforço imediato.

\section{Bibliografia recomendada}

1. American College of Cardiology/ American Heart Association - Clinical competence statement on stress testing. J Am Coll Cardiol 2000;36:1441-53.

2. Atwood JE, Do D, Froelicher V, et al. Can computerization of the exercise test replace the cardiologist? Am Heart J 1998; 136:543-52.

3. Balady GJ, Weiner DA, Rothender JA et al. Arm exercise-thallium imaging testing for the detection of coronary artery disease. J Am Coll Cardiol 1987; 9:84-8.

4. Corra U, Bosimini E. Methodology of exercise test in patients with heart failure. Serial tests: rationale and interpretation of results. Ital Heart J. 2000 Mar; 1(3 Suppl):326-31.

5. Corra U. Methodology of exercise test in patients with heart failure. The cardiopulmonary test: mode of execution, instrumentation, protocols, reproducibility. Ital Heart J. 2000 Mar;1(3 Suppl):320-5.

6. Fregly BJ, Zajac FE, Dairaghi CA. Bicycle drive system dynamics: theory and experimental validation. J Biomech Eng. 2000 Aug;122(4):446-52.

7. Hamm LF et al. Safety and characteristics of exercise testing early after acute myocardial infarction. Am J Cardiol. 1989 May 15;63(17):1193-7.
8. Lima EV, Moffa PJ. Teste ergométrico computadorizado: análise crítica. Arq Bras Cardiol 1995; 65:213-214.

9. Mickelson JK, Bates ER, Parisi AF et al. Is computer interpretation of the exercise electrocardiogram a reasonable surrogate for visual reading? Veterans Affairs ACME Investigators. Clin Cardiol 1997; 20:391-7.

10. Pina IL, Balady GJ, Myers J et al. Guidelines for clinical exercise testing laboratories - a statement for healthcare professionals from the committee on Exercise and Cardiac Rehabilitation. Circulation. 1995;91:912-921.

11. RuDusky BM. Errors of computer electrocardiography. Angiology 1997; 48:1045-50.

12. II Diretrizes da Sociedade Brasileira de Cardiologia sobre teste ergométrico. Arq Bras Cardiol 2002;78(Supl II):1-18.

13. Stuard RJ jr, Ellestad MH. National survey of exercise stress testing facilities. Chest. 1980 Jan;77(1):94-7.

14. Taback L, Marden E, Mason HL. Digital recording of electrocardiographic data for analysis by digital computer. Med Electronics 1959; 6:167. 